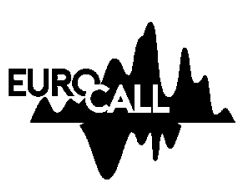

\title{
From local to massive learning: unveiling the (re)design process of an English LMOOC based on InGenio materials
}

\author{
Ana Gimeno-Sanz ${ }^{1}$, Ana Sevilla-Pavón ${ }^{2}$, \\ and Antonio Martínez-Sáez ${ }^{3}$
}

\begin{abstract}
This paper focusses on the (re)design and conversion process of smallscale English as a Foreign Language (EFL) online courseware into a Massive Open Online (Language) Course - or LMOOC, as it is commonly termed - for upperintermediate learners of English offered on $\mathrm{edX}^{4}$, one of the most popular MOOC platforms. It stems from the InGenio First Certificate in English Online Course and Tester (Gimeno-Sanz, Martínez-Sáez, \& Sevilla-Pavón, 2011), which provides university students with autonomous study and self-evaluation materials for the preparation of B2-level ${ }^{5}$ official English language exams. The authors discuss the differences between both platforms and the implications for language learning. They conclude that it is necessary to build language-learning-specific add-ons onto currently available MOOC platforms.
\end{abstract}

Keywords: online learning environments, open educational resources, massive open online language courses, InGenio FCE Online Course \& Tester, upper-intermediate English language MOOC.

\section{Introduction}

After designing and publishing a number of interactive multimedia courseware on CD-ROM, the CAMILLE Research Group at the Universitat Politècnica de

\footnotetext{
1. Universitat Politècnica de València, Valencia, Spain; agimeno@upvnet.upv.es

2. Universitat de Valencia, Valencia, Spain; ana.m.sevilla@uv.es

3. Universidad Politécnica de Madrid, Madrid, Spain; antonio.martinezs@upm.es

4. https://www edx org

5. According to the Common European Framework of Reference for languages (Council of Europe, 2001)
}

How to cite this article: Gimeno-Sanz, A., Sevilla-Pavón, A., \& Martínez-Sáez, A. (2018). From local to massive learning unveiling the (re)design process of an English LMOOC based on InGenio materials. In P. Taalas, J. Jalkanen, L. Bradley \& S Thouësny (Eds), Future-proof CALL: language learning as exploration and encounters - short papers from EUROCALL 2018 (pp. 77-82). Research-publishing.net. 
València (UPV) realised that the internet was rapidly becoming the future of Computer-Assisted Language Learning (CALL) so, at the turn of the century, a group of specialists started designing what was later to be known as the InGenio authoring tool and content manager. As described elsewhere,

"InGenio, at the time (in 2000), was unique in a very important way; it was the first completely online CALL-dedicated authoring tool [- available worldwide -] based on the template approach to authoring (Kitts \& Whittlestone, 1998, p. 4), that allowed language teachers to design their own materials, create a database with these materials - thus making it available to other users -, and automatically convert these materials into learner-ready courses, all on a cloud-computing basis" (Gimeno-Sanz, 2016, p. 1105).

Eighteen years later - a whole generation's worth of advancements in educational technologies - and despite the InGenio courseware still being used by EFL students at UPV, the CAMILLE Research Group decided to convert this Small Private Online Course (SPOC) into an internationally accessible LMOOC.

The resulting LMOOC, 'Upper-Intermediate English' (Gimeno-Sanz, MartínezSáez, \& Sevilla-Pavón, 2018), is based on an English for specific purposes approach. As for the materials it is derived from, they have been piloted, validated and delivered through the InGenio Learning Management System over the past decade. Moreover, they are used by approximately 200 students from UPV every year. The move from a closed, restricted-access, low-scale course to an open, massive online course entails the redesign of the learning objects and resources in order to fit the new format.

The challenges faced during the (re)design process are discussed in the following section, particularly focussing on issues relating to (1) learner assessment and (2) sustainability (or as the conference theme suggests, 'Future-Proof CALL'). This EFL MOOC is the result of a collective effort through which both the developers and the institution are trying to find new ways of making learning more accessible, bearing in mind that education is a basic human right, as established in Article 26 of the United Nations' (1948) Universal Declaration of Human Rights (General Assembly Resolution 217 A, p. 76). Thanks to the use of internet-based tools, participants are granted access to high quality, free-of-charge study and selfassessment learning objects and materials that prepare them for official, highstakes exams. In other words, this delivery mode makes learning more accessible for a larger number of learners, regardless of whether they come from academic or informal learning settings. 


\section{Converting a SPOC into a MOOC: results}

Owing to the fact that the InGenio authoring tool was designed specifically for self-access language learning purposes, it includes a number of features to support the acquisition of a foreign language through autonomous learning. As described in Gimeno-Sanz, Martínez-Sáez, Sevilla-Pavón, and de Siqueira Rocha (2011), some of the discipline-specific features include:

- (a) self-explanatory reference materials (grammar, use of language, etc.),

- (b) text-embedded hints to aid exercise completion,

- (c) immediate and delayed feedback (Pujolà, 2001),

- (d) self-assessment tools and exercises with limitation in number of attempts and time control,

- (e) performance and progress reports, as well as automatic scores,

- (f) help files describing how the online system works, and

- (g) audio enhancements of written text to simulate an immersion scenario.

Of these, only (a), (c), (d), and (e) were part of the edX platform, which meant that other alternatives for $(\mathrm{b}),(\mathrm{f})$, and $(\mathrm{g})$ had to be sought. Provision of hints (b) was resolved by including 'reminders' and references to explanations in exercise headings. For platform functionality help (f), learners are redirected to the general edX learner Help Center, and audio enhancement $(\mathrm{g})$ is provided by including audio files to enhance written text and by designing and embedding a voice-recording tool (Language Lab) in all of the exercises containing audio, allowing learners to compare their utterances to the models provided by native speakers (see Figure 1).

Furthermore, because InGenio courseware is designed to be used autonomously under the supervision of a tutor, with learners organised in closed groups resembling face-to-face educational settings -, its online tutoring system allows tutors/teachers to access learner-generated audio and open text output, which can subsequently be corrected, marked, and scored. These scores are then automatically averaged with those calculated by the system itself (Sevilla-Pavón, Martínez-Sáez, $\&$ Macario de Siqueira, 2011). Consequently, due to the huge number of MOOC 
enrollees, this was one of the main features that had to be redesigned. In the MOOC version of the course, several solutions were found:

- Specially designed rubrics are provided to aid in self- and peer-assessment of learner-generated open text (writing practice exercises).

- Pronunciation and fluency practice is catered for by prompting learners to transcribe their oral production, requesting them to access external free text-to-speech software and, ultimately, have the software reproduce the written transcription of their oral text ${ }^{6}$. Correct oral reproduction of the written input is interpreted as an indication of success.

Another unique feature is InGenio's ability to create course-independent glossaries (which open up in pop-up windows upon clicking on a 'hot word') that authors can link to in any exercise. In the edX LMOOC, however, this deficiency was solved by incorporating automatically generated glossaries for each of the study units inserted into the Multidict dictionary interface ${ }^{7}$, thus allowing learners to quickly seek definitions or translations into more than 100 languages - a true asset when considering that edX enrollees come from all five continents.

Lastly, whereas InGenio courseware users can upload recorded sound files for their tutors to correct and mark, given the enrolment numbers on edX - ranging in the tens of thousands -, upon designing the MOOC, the decision was made to compensate this absence, as described in Gimeno-Sanz (2017), by:

- organising scheduled instructor-led Google Hangouts ${ }^{8}$ sessions to support synchronous oral interaction, and

- organising learner-driven speaking practice sessions using the Talkabout discussion planner, a tool that serves the purpose of organising speaking practice encounters so that students can interact live among themselves and practise the foreign language together through a Google Hangouts video conference.

6. https://www.naturalreaders.com/online

7. http://multidict.net

8. For more information, go to https:/hangouts.google com 
Figure 1. Sample reading comprehension exercise from the upper-intermediate EFL MOOC on the edX platform

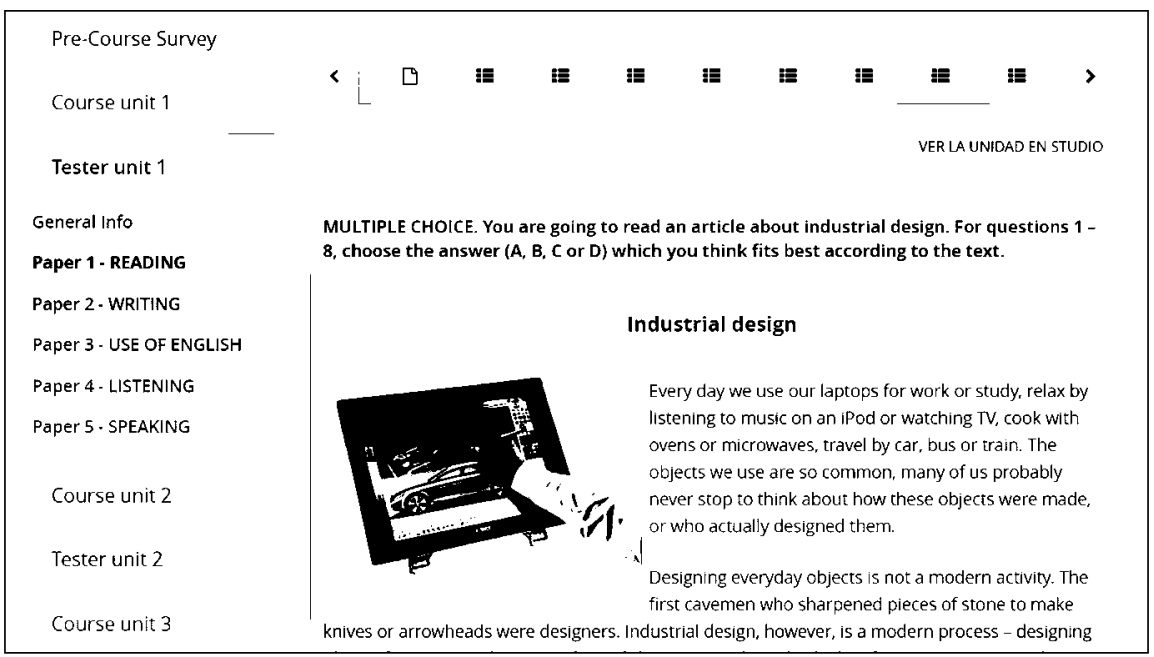

\section{Conclusions}

In order to gain in sustainability due to funding limitations at UPV to appropriately maintain and update the InGenio System, the CAMILLE Research Group decided to (re)design and transfer the InGenio FCE Course \& Tester to the edX MOOC platform. This had major implications in terms of writing and speaking practice activities for which the MOOC platform was not prepared. This procedure has also proven that - as so many times warned in CALL systems and materials development - it is, in effect, not necessary to 'reinvent the wheel' by ensuring that the lessons learnt from the past are taken into account in present day CALL software development and implementation.

\section{References}

Council of Europe (2001). Common European framework of reference for languages. Cambridge University Press.

Gimeno-Sanz, A. (2016). Moving a step further from "integrative CALL". What's to come? Computer Assisted Language Learning, 29(6), 1102-1115. https://oi.org/10.1080/095882 21.2015.1103271 
Gimeno-Sanz, A. (2017). Designing a MOOC for learners of Spanish: exploring learner usage and satisfaction. In K. Borthwick, L. Bradley \& S. Thouësny (Eds), CALL in a climate of change: adapting to turbulent global conditions - short papers from EUROCALL 2017 (pp. 122-127). Research-publishing.net. https://doi.org/10.14705/rpnet.2017.eurocall2017.700

Gimeno-Sanz, A., Martínez-Sáez, A., \& Sevilla-Pavón, A. (2011). InGenio FCE Online Course \& Tester: Universitat Politècnica de València.

Gimeno-Sanz, A., Martínez-Sáez, A., \& Sevilla-Pavón, A. (2018). Upper-intermediate English. https:/www.edx.org/es/professional-certificate/upvalenciax-upper-intermediate-english

Gimeno-Sanz, A., Martínez-Sáez, A., Sevilla-Pavón, A., \& de Siqueira Rocha, J. M. (2011) Fostering autonomy in a pedagogically sound e-learning environment for learners of English for specific purposes. In S. Maruenda-Bataller \& B. Clavel-Arroitia (Eds), Multiple voices in academic and professional discourse: current issues in specialised language research, teaching and new technologies (pp. 547-560). Cambridge Scholar Publishing.

Kitts, S. A., \& Whittlestone, K. (1998). CALScribe: a multimedia template ideal for CALL development. ReCALL, 10(2), 4-11. https://doi.org/10.1017/S0958344000003682

Pujolà, J. T. (2001). Did CALL feedback feed back? ReCALL, 13(1), 79-98. https://doi. org $/ 10.1017 /$ S0958344001000817

Sevilla-Pavón, A., Martínez-Sáez, A., \& Macario de Siqueira, J. (2011). Self-assessment and tutor assessment in online language learning materials: InGenio FCE Online Course and Tester. In S. Thouësny \& L. Bradley (Eds), Second language teaching and learning with technology: views of emergent researchers (pp. 45-69). Research-publishing.net. https://doi. org/10.14705/rpnet.2011.000006

United Nations. (1948). Universal declaration of human rights. http://www.un.org/en/universaldeclaration-human-rights 